\title{
Correction to: First report of citrus tristeza virus trifoliate resistance-breaking (RB) genotype in Citrus grandis in China
}

\author{
Jun Wang ${ }^{1,2} \cdot$ Tianyu Zhou ${ }^{1,2} \cdot$ Mengji Cao ${ }^{1,2} \cdot$ Yan Zhou $^{1,2} \cdot$ Zhongan Li $^{1,2}$ \\ Published online: 26 November 2018 \\ (C) Società Italiana di Patologia Vegetale (S.I.Pa.V.) 2018
}

Correction to: Journal of Plant Pathology

https://doi.org/10.1007/s42161-018-0169-9

The article was published without acknowledgements, and no statements about ethical issues or conflict of interests. This correction stands to correct the original article with the following:

Acknowledgments This work was partially supported by Intergovernmental International Science, Technology and Innovation (STI) Collaboration Key Project of China's National Key R\&D Programme (NKP) (2017YFE0110900) and Chongqing Research Program of Basic Research and Frontier Technology (cstc2015jcyjBX0043, cstc2017jcyjAX0150).

The original article has been corrected.

The online version of the original article can be found at https://doi.org/ 10.1007/s42161-018-0169-9

Yan Zhou

zhouyan@cric.cn

Zhongan Li

zhongan@cric.cn

1 National Citrus Engineering Research Center, Citrus Research Institute, Southwest University, Chongqing 400712, China

2 Academy of Agricultural Sciences, Southwest University, Chongqing 400715, China 